\title{
A Rare Case of Completely Ambicoloured Atlantic Halibut, Hippoglossus hippoglossus, from the Lower St. Lawrence Estuary, Quebec
}

\author{
Denis Chabot and Roberta Miller
}

Direction des sciences halieutiques et de l'aquaculture, Institut Maurice-Lamontagne, Pêches et Océans Canada, C.P. 1000, Mont-Joli, Québec G5H 3Z4 Canada

Chabot, Denis, and Roberta Miller. 2007. A rare case of completely ambicoloured Atlantic Halibut, Hippoglossus hippoglossus, from the lower St. Lawrence estuary, Quebec. Canadian Field-Naturalist 121(1): 35-39.

\begin{abstract}
An Atlantic Halibut (Hippoglossus hippoglossus) (41.4 cm fork length) with the same pigmentation on the blind side as on the ocular side (ambicoloration) was captured in the lower St. Lawrence estuary, Canada, on 24 June 2004. This specimen represents the most extreme case of ambicoloration published for this species to date. As in other cases of extreme ambicoloration, this specimen shows other signs of abridged metamorphosis and reduced asymmetry, such as incomplete migration of the left eye and a hooked dorsal fin. Studies of hatchery-reared larvae have shown that the most common cause of malpigmentation, including ambicoloration, in halibut is a diet containing inadequate amounts and proportions of essential unsaturated fatty acids shortly before metamorphosis. Even though not expected to be common in the wild, inadequate diet for a short duration before metamorphosis is the most likely cause of ambicolouration in wild halibut.
\end{abstract}

Key words: Atlantic Halibut, Hippoglossus hippoglossus, ambicolouration; malpigmentation, metamorphosis, eye migration, hooked dorsal fin, St. Lawrence estuary, Quebec.

Flatfish larvae are normally pigmented on both sides, whereas juveniles and adults are usually pigmented only on their ocular side. Once metamorphosis begins, larval-type melanophores (pigment cells containing melanin) on the blind side go through cytolysis whereas developing adult melanophores differentiate on the ocular side (Norman 1934; Venizelos and Benetti 1999; Bolker and Hill 2000). However, some pleuronectiforms both wild and hatchery reared, have abnormal pigmentation patterns (Wheeler 1969; Gartner 1986; Bolker and Hill 2000). Malpigmentation ranges from deficiencies of pigmentation on the ocular side (hypomelanosis or pseudoalbinism) to an excess of pigmentation on the blind side (hypermelanosis or ambicoloration) (Venizelos and Benetti 1999; Bolker and Hill 2000).

Norman (1934) divided ambicolouration into three categories: staining, spotting and true ambicoloration. Staining is the development of irregular pigmented patches on the blind side that are lighter than the pigmentation of the eyed side and lack the characteristic spots and markings of the latter. Spotting is the presence of black or brown spots, in irregular or regular arrangement; the spots that are present occupy the same position as the characteristic dark spots found on the ocular side. Finally, true ambicoloration is when the coloring on the blind side is the same as that on the ocular side; true ambicoloration is often partial, involving the posterior part of the body while the head and a variable proportion of the anterior part remain white on the blind side. Very occasionally flatfish are completely ambicolored (Norman 1934).

Juvenile and adult Atlantic Halibut, Hippoglossus hippoglossus, are olive or slaty brown with some black on the ocular (right) side and strikingly white on the blind side, although the blind side can be of a more or less uniform grayish cast, or blotched with gray or even red, in older specimens (Gudger and Firth 1935; Scott and Scott 1988; Collette and Klein-MacPhee 2002). Here we describe a completely ambicoloured Atlantic Halibut and review the few past mentions of malpigmented Atlantic Halibut as well as studies dealing with possible causes of malpigmentation in general, and ambicolouration in particular.

\section{Results}

An Atlantic Halibut with a total length (TL) of $42.6 \mathrm{~cm}$ and a fork length (FL) of $41.4 \mathrm{~cm}$ was captured by bottom-trawling in the lower St Lawrence estuary, $48^{\circ} 56^{\prime} \mathrm{N}, 67^{\circ} 26^{\prime} \mathrm{W}$ on 24 June 2004 (depth $=90-100 \mathrm{~m}$, temperature $=0.5-1 \cdot 1^{\circ} \mathrm{C}$ ). Nine normally-pigmented H. hippoglossus were captured during the 56 sets fished over 6 days in this area. No ambicolored Atlantic Halibut was captured during the annual survey of the northern Gulf of St. Lawrence and lower estuary for the years 1990-2005. This bottom-trawl survey was conducted by the Department of Fisheries and Oceans Canada in August and early September every year. A total of 310 normally-pigmented H. hippoglossus was captured in 3715 trawl sets during this period.

The blind side of the ambicoloured fish was exactly the same colour as the ocular side, except for a lack of pigmentation on the distal half of the pectoral fin and one small white spot $(1-2 \mathrm{~mm})$ in the middle of the left side. The anterior end of its dorsal fin had grown into a hook detached from the head. Furthermore, the left eye had not completed its migration to the right side and remained partly visible from the blind side. Photos of the ocular and blind sides of this fish are shown in Figure 1. For comparison, a normal Atlantic Halibut 

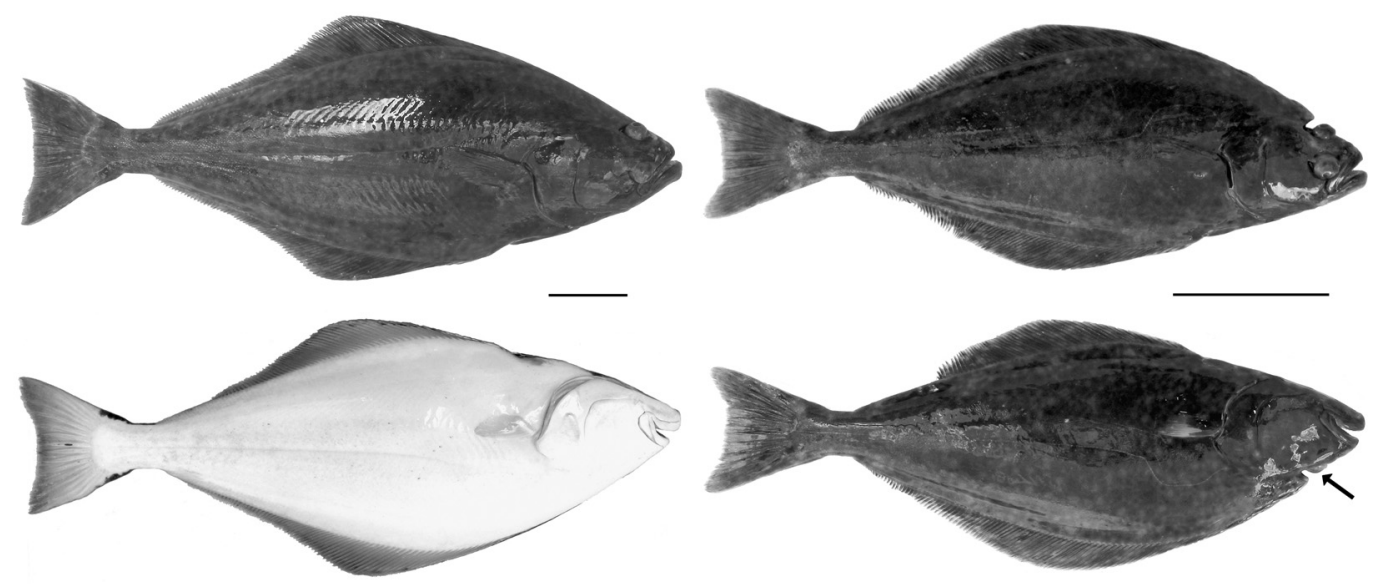

FIGURE 1. Ocular (top) and blind side (bottom) of a normal (left) and ambicoloured (right) Atlantic Halibut, Hipoglossus hippoglossus. A 10-cm scale bar is shown next to each fish. The left eye of the ambicoloured fish has not completed its migration and is partly visible from the blind side (arrow). Pale areas on the blind side of the head of ambicoloured fish are caused by light reflection: pigmentation was the same as on the ocular side.

(85.9 $\mathrm{cm}$ TL and $84.7 \mathrm{~cm}$ FL [Fork Length]) captured at about the same location on 25 June 2004 (depth = $120-130 \mathrm{~m}$, temperature $=1.8-2.0^{\circ} \mathrm{C}$ ) is also shown.

\section{Discussion}

An almost completely ambicoloured Atlantic Halibut was described by Gudger and Firth (1935). Like the present specimen, it had a hooked dorsal fin and incompletely rotated left eye. Unlike the present specimen, about $30 \%$ of the blind side of the head was white, and except for the distal half of the pectoral and caudal fins, the remainder of the blind side was darker in colour than the ocular side, almost black. Gudger and Firth (1937) mention two other H. hippoglossus that were partially ambicoloured and reversed (the eyes were on the left side). A literature search revealed no further occurrences of wild ambicoloured halibut. However, malpigmentation is common in hatchery-reared Atlantic halibut and ambicoloration is often accompanied by a hooked dorsal fin and incomplete eye migration (Næss et al. 1995; Pittman et al. 1998).

Bolker and Hill (2000) discussed two possible explanations for malpigmentation. The first hypothesis asserts that the development of the normal pigmentation asymmetry in flatfish is associated with the development of a fundamental left-right distinction. The lack of development of adult melanophores on the blind side is not due to the lack of precursor cells, but rather to a difference in the histological structure of the skin on both sides of the fish (Seikai and Matsumoto 1994). Failure of this differentiation to develop can prevent adult melanophore development on the ocular side and result in pseudoalbinism. Although not as thoroughly studied, ambicoloration could also be explained in this manner. The second hypothesis to explain malpig- mentation, or at least pseudoalbinism, involves dieterybased abnormal development of the retina. The resulting visual defects are thought to lead to a failure of a hormonal signal necessary for melanophore development on the ocular side. Bolker and Hill (2000) noted that the two hypotheses were not mutually exclusive.

Incomplete eye migration could be the cause of ambicoloration if optical signals were still interpreted by the brain as coming from the blind side, resulting in ocular-side melanophore development on the blind side. However, this hypothesis is not supported by the results of studies of hatchery reared Atlantic Halibut, where ambicoloration was found in fish that had complete eye migration (e.g., Hamre et al. 2002), and conversely, both normally coloured and ambicoloured Atlantic Halibut exhibited a lack of eye migration (Pittman et al. 1998).

In wild fish, partial ambicoloration is usually not associated with other abnormalities, whereas Norman (1934) and Gudger and Firth (1936) noticed that in almost completely ambicoloured flatfish with pigmentation on at least $25-35 \%$ of the blind side of the head, eye migration was usually incomplete and the anterior end of the dorsal fin was hooked. Incomplete eye migration and the presence of a hooked dorsal fin are expected to occur together: pterygiophores (bones supporting the dorsal fin) normally expand towards the snout during metamorphosis, after the left eye clears the dorsal crest (Norman 1934; Gudger and Firth 1935; Brewster 1987). Incomplete eye migration, where the left eye does not clear the dorsal crest, prevents normal pterygiophore expansion. Furthermore incomplete eye migration is accompanied by incomplete torsion of the neurocranium, resulting in the formation of a hooked dorsal fin (Sæle et al. 2004). Total or nearly 
total ambicoloration is also accompanied by other abnormalities such as pectoral fins that are more equal in length than in normally pigmented fish, and the presence of the same type of scales on the coloured areas of the blind side as those on the ocular side.

As pointed out by Norman (1934), the anterior part of the head is coloured only in the most complete cases of ambicoloration and is also the most asymmetrical part of a flatfish. Thus the available observations indicate that the gradient in ambicoloration corresponds to a gradient in the level of perturbation during metamorphosis. Pigmentation of a small proportion of the blind side is a minor developmental defect, whereas complete ambicoloration is a sign of more profound disturbances resulting in a less complete metamorphosis, i.e., a reduction of asymmetry including incomplete eye migration and almost complete pigmentation of the blind side. However, the causes of these developmental defects are not well understood, especially for wild fish.

Many possible causes of malpigmentation have been proposed that involve flatfish larvae before or during metamorphosis, including diet, water quality, stocking density, extreme temperature, UV light, stress and genetic factors (for reviews see Gartner 1986; Seikai and Matsumoto 1994; Venizelos and Benetti 1999; Bolker and Hill 2000; Hamre et al. 2005). Inadequate diet is now thought to be the most important cause of malpigmentation. Pseudo albinism was a very common problem when hatcheries started to grow halibut larvae and fed them artemia. This was alleviated when larvae were fed a natural copepod-based diet during a specific premetamorphic stage that constitutes a critical period (Næss et al. 1995; Næss and Lie 1998; Shields et al. 1999). In particular, levels and proportions of essential unsaturated fatty acids are important for successful pigmentation. Artemia are low (in proportion of total lipids) in docosahexaenoic acid (DHA) and eicosapentaenoic acid (EPA) and high in arachidonic acid (ARA) compared with copepods (Næss et al. 1995; Copeman et al. 2002; Hamre et al. 2005). High levels of DHA resulting in a DHA/EPA ratio $>1$, reduced levels of ARA and high EPA/ARA ratios decrease the incidence of pseudoalbinism, incomplete eye migration and hooked dorsal fin (Næss et al. 1995; McEvoy et al. 1998a; Næss and Lie 1998; Shields et al. 1999; Hamre et al. 2002). Other nutritional differences between artemia and copepods may contribute to pigmentation, such as the greater proportion of polar lipids (McEvoy et al. 1998b), vitamin A (or its precursors, carotenoid compounds) and iodine (Hamre et al. 2005) in copepods.

Less attention has been paid to the development of ambicoloration. It can be voluntarily produced in the Japanese Flounder, Paralichthys olivaceus, by immersing larvae in water containing retinoic acid (Haga et al. 2005). Ambicoloration is an undesirable trait in hatcheries that is not normally induced voluntarily, but rather occurs spontaneously at incidence rates that depend on diet. Most diets that reduce the incidence of pseudoalbinism also increase the incidence of hypermelanosis of the blind side (for a review, see Haga et al. 2004). For instance, an excess of vitamin $D_{3}$ (Hasegawa et al. 1998; Haga et al. 2004) or A (Miwa and Yamano 1999) can increase the rate of ambicoloration in the Japanese Flounder. In Atlantic Halibut, copepod-based diets sometimes resulted in ambicoloration for up to $30-40 \%$ of the fish (Shields et al. 1999; Hamre et al. 2002; Hamre et al. 2005), but in other studies it did not (Næss et al. 1995; Næss and Lie 1998). This is likely the result of variability in nutritional properties of the copepods used, as the quantities and ratios of unsaturated fatty acids, vitamins and other nutrients changed between batches or size-classes of copepods within and between studies (e.g., Næss et al. 1995; McEvoy et al. 1998a; Shields et al. 1999; Hamre et al. 2002). Dietinduced ambicoloration is conceivable in wild halibut as well: hatching time, egg condition and environmental conditions all influence when larvae begin to metamorphose and the availability and quality of prey items. Laboratory studies have shown that the critical period during which diet influences the development of postmetamorphic pigmentation is short, making it possible for wild fish to have a suboptimal diet near the beginning of metamorphosis and become ambicoloured.

Malpigmentation can also occur in post-metamorphic flatfish. Many wild fingerlings of Speckled Flounder (Paralichthys woolmani) that were normally pigmented when captured developed white spots on their ocular side within a few days. Most of them returned to a normal pigmentation within one year, except for a few that retained some pigmentation on their blind side (Benetti 1997; Venizelos and Benetti 1999). Light reaching the blind side where it is not in contact with the bottom, and lack of sediment in which fish can bury themselves can also result in some pigmentation on the blind side of flatfish (Cunningham 1893; Ottesen and Strand 1996). However these are examples of staining, not ambicoloration. True ambicoloration appears to be in place soon after metamorphosis.

It is difficult to assess whether factors leading to malpigmentation in hatchery-reared halibut would do so in the wild, or if these factors are even relevant in the wild. Halibut larvae likely encounter appropriate prey items in the wild. However, considering the high incidence of malpigmentation when diet is inappropriate for only a few days in hatcheries, and the fact that non-diet related causes of malpigmentation in captive Atlantic Halibut (light, sediment type, stocking density, etc.) are even less likely to be problematic in the wild, diet is the most likely of the known causes of malpigmentation to occur in the wild. Other possible causes, such as a genetic causes, remain possible, however. True albinism (i.e., presence of red eyes) is inheritable in the Japanese Flounder (Shikano 2005), but diet appears much more important than genetic factors in the development of pseudo-albinism and ambicolouration (Seikai and Matsumoto 1994). 
Few wild ambicoloured Atlantic Halibut have been reported, but reporting rate is unknown. Reporting malpigmentation should be encouraged in scientific surveys for this species as well as others to assess incidence and mortality rate of ambicoloured fish and improve our understanding of the causes of ambicolouration in Atlantic Halibut, and of taxonomically related incidence rates in flatfish (e.g., Díaz de Astarloa et al. 2006).

The specimen presented in this study has been preserved and is part of the Maurice-Lamontagne Institute Collection (accession number 11633).

\section{Acknowledgments}

We thank G. Hogan and V. Puvanendran for their helpful comments on an earlier version of the manuscript.

\section{Literature Cited}

Benetti, D. D. 1997. Spawning and larval husbandry of flounder (Paralichthys woolmani) and pacific yellowtail (Seriola mazatlana), new candidate species for aquaculture. Aquaculture 155: 307-318.

Bolker, J. A., and C. R. Hill. 2000. Pigmentation development in hatchery-reared flatfishes. Journal of Fish Biology 56: 1029-1052.

Brewster, B. 1987. Eye migration and cranial development during flatfish metamorphosis: A reappraisal (Teleostei Pleuronectiformes). Journal of Fish Biology 31: 805-833.

Collette, B. B., and G. Klein-MacPhee. Editors. 2002. Bigelow and Schroeder's Fishes of the Gulf of Maine. Third edition. Smithsonian Institution Press, Washington, DC.

Copeman, L. A., C. C. Parrish, J. A. Brown, and M. M. Harel. 2002. Effects of docosahexaenoic, eicosapentaenoic, and arachidonic acids on the early growth, survival, lipid composition and pigmentation of yellowtail flounder ( $\mathrm{Lim}$ anda ferruginea): a live food enrichment experiment. Aquaculture 210: 285-304.

Cunningham, J. T. 1893. Researches on the coloration of the skins of flatfishes. Journal of the Marine Biological Association of the United Kingdom III: 111-118.

Díaz de Astarloa, J. M., R. Rico, and M. Acha. 2006. First report of a totally ambicoloured Patagonian flounder Paralichthys patagonicus (Paralichthyidae) with dorsal fin anomalies. Cybium, Revue Internationale d'Ichtyologie 30: 73-76.

Gartner, J. V., Jr. 1986. Observations on anomalous conditions in some flatfishes (Pisces: Pleuronectiformes), with a new record of partial albinism. Environmental Biology of Fishes 17: 141-152.

Gudger, E. W., and F. E. Firth. 1935. An almost totally ambicolorate halibut, Hippoglossus hippoglossus, with partially rotated eye and hooked dorsal fin-The only recorded specimen. American Museum Novitates 811: 1-7.

Gudger, E. W., and F. E. Firth. 1936. Three partially ambicolorate four-spotted flounders, Paralichthys oblongus, two each with a hooked dorsal fin and a partially rotated eye. American Museum Novitates 885: 1-9.

Gudger, E. W., and F. E. Firth. 1937. Two reversed partially ambicolorate halibuts: Hippoglossus hippoglossus. American Museum Novitates 925: 1-10.
Haga, Y., T. Takeuchi, Y. Murayama, K. Ohta, and T. Fukunaga. 2004. Vitamin $D_{3}$ compounds induce hypermelanosis on the blind side and vertebral deformity in juvenile Japanese flounder Paralichthys olivaceus. Fisheries Science 70: 59-67.

Haga, Y., K. Nataami, and T. Takeuchi. 2005. Process of true ambicoloration in larval and juvenile Japanese flounder Paralichthys olivaceus: An ultrastructural study. Nippon Suisan Gakkaishi [Japanese Edition] 71: 782-790.

Hamre, K., I. Opstad, M. Espe, J. Solbakken, G. Hemre, and K. Pittman. 2002. Nutrient composition and metamorphosis success of Atlantic halibut (Hippoglossus hippoglossus, L.) larvae fed natural zooplankton or Artemia. Aquaculture Nutrition 8: 139-148.

Hamre, K., M. Moren, J. Solbakken, I. Opstad, and K. Pittman. 2005. The impact of nutrition on metamorphosis in Atlantic halibut (Hippoglossus hippoglossus L.). Aquaculture 250: 555-565.

Hasegawa, Y., T. Takeuchi, E. Itagaki, and T. Fukunaga. 1998. Relationship between fat soluble vitamins in diet and the occurrence of colour abnormality on the blind side of juvenile Japanese flounder. Suisanzoshoku 46: 279-286.

McEvoy, L. A., A. Estevez, J. G. Bell, R. J. Shields, B. Gara, and J. R. Sargent. 1998a. Influence of dietary levels of eicosapentaenoic and arachidonic acids on the pigmentation success of turbot (Scophthalmus maximus L.) and halibut (Hippoglossus hippoglossus L.). Bulletin of the Aquaculture Association of Canada 98: 17-20.

McEvoy, L. A., T. Næess, J. G. Bell, and Ø. Lie. 1998b. Lipid and fatty acid composition of normal and malpigmented Atlantic halibut (Hippoglossus hippoglossus) fed enriched Artemia: a comparison with fry fed wild copepods. Aquaculture 163: 235-248.

Miwa, S., and K. Yamano. 1999. Retinoic acid stimulates development of adult type chromatophores in the flounder Journal of Experimental Zoology 284: 317-324.

Næss, T., M. Germain-Henry, and K. E. Naas. 1995. First feeding of Atlantic halibut (Hippoglossus hippoglossus) using different combinations of Artemia and wild zooplankton. Aquaculture 130: 235-250

Næss, T., and Ø. Lie. 1998. A sensitive period during first feeding for the determination of pigmentation pattern in Atlantic halibut, Hippoglossus hippoglossus L., juveniles: the role of diet. Aquaculture Research 29: 925-934.

Norman, J. R. 1934. A systematic monograph of the flatfishes (Heterosomata) Volume I Psettodidae, Bothidae, Pleuronectidae. British Museum, London. viii +459 pages.

Ottesen, O. H., and H. K. Strand. 1996. Growth, development, and skin abnormalities of halibut (Hippoglossus hippoglossus L.) juveniles kept on different bottom substrates. Aquaculture 146: 17-25.

Pittman, K., A. Jelmert, T. Næss, T. Harboe, and K. Watanabe. 1998. Plasticity of viable postmetamorphic forms of farmed Atlantic halibut, Hippoglossus hippoglossus L. Aquaculture Research 29: 949-954.

Sæle, Ø., J. S. Solbakken, K. Watanabe, K. Hamre, D. Power, and K. Pittman. 2004. Staging of Atlantic halibut (Hippoglossus hippoglossus L.) from first feeding through metamorphosis, including cranial ossification independent of eye migration. Aquaculture 239: 445-465.

Scott, W. B., and M. G. Scott. 1988. Atlantic fishes of Canada. Canadian Bulletin of Fisheries and Aquatic Sciences 219. $x x x+731$ pages. 
Seikai, T., and J. Matsumoto. 1994. Mechanism of pseudoalbinism in flatfish: an association between pigment cell and skin differentiation. Journal of the World Aquaculture Society 25 : $78-85$.

Shields, R. J., J. G. Bell, F. S. Luizi, B. Gara, N. R. Bromage, and J. R. Sargent. 1999. Natural copepods are superior to enriched artemia nauplii as feed for halibut larvae (Hippoglossus hippoglossus) in terms of survival, pigmentation and retinal morphology: relation to dietary essential fatty acids. Journal of Nutrition 129: 1186-1194.
Shikano, T. 2005. Marker-based estimation of heritability for body color variation in Japanese flounder Paralichthys olivaceus. Aquaculture 249: 95-105.

Venizelos, A., and D. D. Benetti. 1999. Pigment abnormalities in flatfish. Aquaculture 176: 181-188.

Wheeler, A. C. 1969. The fishes of the British Isles and North-West Europe. Macmillan, London, xvii + 613 pages.

Received 3 August 2006

Accepted 22 February 2007 